\title{
TENSIÓN ENTRE DERECHOS Y PRINCIPIOS. CONSIDERACIONES A LA INTERPRETACIÓN JUDICIAL DE LA MORAL EN LA PRAXIS DEL DERECHO
}

\author{
Jorge ENRIQUe LeÓn Molina \\ Universidad Católica de Colombia
}

\begin{abstract}
Resumen
Dworkin afirma que todas las proposiciones jurídicas tienen un papel en la compleja red que compone el sistema jurídico y, además, son capaces de tener un sentido determinado en dicha red; así las cosas, en los casos en que los jueces enfrenten problemas que incluyan estándares morales -como la tortura, el aborto o la eutanasia- en virtud de los cuales no se puede determinar la verdad o la falsedad de la proposición tampoco es posible definir si es jurídica o no, a la hora de determinar su importancia práctica.
\end{abstract}

Es conveniente establecer si los criterios morales pueden indicar la verdad de las normas jurídicas (entendidas como proposiciones jurídicas) y, en caso de que sean ciertas, en qué eventos específicos pueden serlo. Lo que se procura es determinar si los jueces tienen en cuenta criterios morales para decidir si una determinada proposición jurídica es verdadera.

Palabras clave: derechos, moral, normas, juez.

El autor: abogado de la Universidad Católica de Colombia, maestrando en Filosofía del Derecho de la Universidad Libre, sede Bogotá. Docente de tiempo completo de la Universidad Católica de Colombia e investigador adscrito al Grupo de estudios Legales y Sociales Phronesis. Correo electrónico: león_0904@hotmail.com

Recibido: 4 de marzo de 2013; evaluado: 21 de junio de 2013; aceptado: 24 de junio de 2013. 


\title{
TENSION BETWEEN RIGHTS AND PRINCIPLES. CONSIDERATIONS ON MORAL LEGAL INTERPRETATION IN THE PRAXIS OF LAW
}

\author{
Jorge Enrique León Molina \\ Universidad Católica de Colombia
}

\begin{abstract}
Dworking states that all legal propositions have a role in the complex network that composes the legal system and, also, they are able to have a determined meaning in that network; in such a manner, in the cases where judges face problems that include moral standards -such as torture, abortion or euthanasia- by virtue of the difficulty to determine the truth or falsity of the proposition, is neither possible to define if its legal or not, when establishing its practical importance.

It is convenient to establish if moral criteria could indicate the thruth of legal norms (understood as legal propositions) and, in case they are thruth, in what events could they be. The purpose is to establish if judges consider these moral criteria into when deciding if a certain legal proposition is true.
\end{abstract}

Keywords: Rights, moral, norms, judge.

About the author: Lawyer from Universidad Catolica de Colombia, Master Candidate in Philosophy of Law from Universidad Libre, Bogota Campus. Full time professor at Universidad Catolica de Colombia and researcher assigned to the Legal Studies and Social Phronesis Group. Bogotá. E-mail: león_0904@hotmail.com

Received: March 4, 2013; reviewed: June 21, 2013; accepted: June 24, 2013 


\section{Criterios del concepto de Derecho y aplicación de los juicios morales}

De acuerdo con la ciencia con la que se relacione, Dworkin plantea varios criterios para entender el Derecho. Veamos:

\subsection{Concepto sociológico del Derecho}

Se entiende el Derecho como una clase de estructura social institucionalizada limitada por el concepto doctrinal del Derecho, dado que nada puede ser considerado como un sistema jurídico en sentido sociológico sin preguntarse cuáles derechos y obligaciones reconoce. Esto no es recíproco, puesto que no todo el conjunto de normas que desarrolla derechos y obligaciones es considerado un sistema jurídico. ${ }^{1}$

\subsection{Concepto taxonómico del Derecho}

Mediante este concepto, empleado por un grupo reducido de iusfilósofos, se entiende que toda comunidad política organizada por medio del Derecho, en el sentido sociológico, también posee un conjunto de reglas concretas que son de naturaleza jurídica, diferentes a las reglas morales, consuetudinarias o de otro tipo. Esta noción le plantea a los iusfilósofos la siguiente pregunta: ¿Es posible que los principios morales sean también considerados como principios jurídicos? O, de otra forma, ¿de qué manera es relevante la moral a la hora de decidir cuáles proposiciones jurídicas son verdaderas?

\subsection{Concepto aspiracional del Derecho}

Según Dworkin, también es llamado imperio de la ley o ideal de la legalidad. Este controvertido concepto divaga en cuanto a su definición, por lo que se hace necesario representarlo de dos formas:

- Un grupo de iusfilósofos afirma que el imperio de la ley es un ideal de carácter formal, dado que se satisface cuando las autoridades se obligan a actuar

\footnotetext{
Es importante afirmar que el concepto sociológico del Derecho nos permite determinar una relación entre los derechos y las obligaciones presentes en el marco de un determinado sistema jurídico; sin embargo, no todo conjunto de normas que desarrolla derechos y obligaciones es un Sistema. Ronald Dworkin, La justicia con toga. (Madrid: Marcial Pons S. A., 2010), 15.
} 
únicamente como lo tienen permitido en unos estándares preestablecidos y así lo hacen.

- $\quad$ Otro grupo afirma que el imperio de la ley es un ideal de carácter sustancial, puesto que entienden que la legalidad existe solo cuando las autoridades respetan un conjunto de derechos de carácter fundamental a los ciudadanos.

La distinción entre estas concepciones ha suscitado enconados debates entre constitucionalistas -estadounidenses, según Dworkin- que permitirían delimitar e imponer límites sustantivos a los conceptos del Derecho.

Al preguntarnos por la aplicación de la moral en el Derecho, hacemos referencia a la naturaleza del concepto doctrinal de este, el cual se puede abordar desde varios puntos de vista:

- Dworkin nos invita a rechazar la idea, un tanto simplista, de que todo Derecho injusto es inválido, ${ }^{2}$ porque el contenido del Derecho puede depender de la justicia en diversas formas, por ejemplo, cuando un determinado Estado tiene una Constitución que impone límites morales al Derecho que pueda desarrollarse en su territorio.

- Hay ocasiones en las que lo que establece este depende de lo que el Derecho debería establecer, pues en muchas Naciones del mundo está contenido en leyes, reglamentos u otras normas escritas, cuyo texto puede presentar ambigüedades, vaguedades o una abstracción excesiva, mientras que en los sistemas jurídicos anglosajones la condición de verdad o falsedad de las proposiciones jurídicas no solo radica en normas escritas, sino también en decisiones judiciales dadas en ese sistema; en conclusión, las decisiones jurisprudenciales complementan las disposiciones legales.

Todo esto se enfoca a los principios como criterios jurídicos inherentes al sistema, que son aplicables al sistema jurídico en la medida en que se presenten casos difíciles, en los que una simple regla de subsunción no es posible. En tal caso, el juez está facultado para escoger la opción que considere correcta. Esa atribución, en principio tan arbitraria, se circunscribe al amplio conocimiento que el juez posee;

2 Dado que pueden existir disposiciones meramente injustas, pero a pesar de ello, las proposiciones que las describen son verdaderas. Dworkin, La justicia con toga, 16. 
aquí, una aparente discrecionalidad queda reducida a la utilización de criterios morales propios del sistema, evidenciables en su historia jurisprudencial propia. ${ }^{3}$

\section{Robert Alexy y la teoría discursiva del Derecho}

Alexy procura desarrollar una teoría del discurso jurídico, producto de la similitud que padece la interpretación judicial con el discurso racional, en donde la prevalencia de un derecho fundamental sobre otro de la misma jerarquía será determinada por un factor argumentativo. El modelo discursivo de la interpretación jurídica es propuesto para reemplazar modelos clásicos de interpretación jurídica que presentan déficits, como el modelo deductivo, decisorio, hermenéutico y de coherencia. ${ }^{4}$

- $\quad$ El modelo deductivo como modelo de interpretación judicial se circunscribe a la deducción de una solución a una situación de hecho establecida en el Derecho; de esa manera, solo existe una solución posible para cada caso. Este modelo queda corto respecto al choque de derechos de igual jerarquía, por la vaguedad del lenguaje utilizado en el Derecho.

- El modelo decisorio surge de la insuficiencia del modelo deductivo para resolver los casos difíciles, ya que según este modelo de interpretación, el juez actúa como legislador cuando el sistema normativo no puede ofrecer una solución satisfactoria a un caso difícil. Fue propuesto por Kelsen para resolver lo que llamó problema jurídico-político. Sin embargo, este esquema ignora la evidencia en un proceso y la obligación legal de los jueces que deben decidir de acuerdo con parámetros judiciales y racionales; así, no estarían legislando, sino ampliando el campo de interpretación de una norma.

- El modelo hermenéutico, por su parte, fue desarrollado en el siglo XX y tiene como sus grandes representantes a Gadamer y Kauffman. Se caracteriza por sus tres círculos de interpretación: el primero se refiere a la preconcepción y

Según Dworkin, al hablar de discreción se habla del conjunto de información que constituye el marco de información de quien se vale de ella para resolver una situación sometida a estudio; así, es inútil toda definición exacta del término "discreción" sin tratar de sopesarla según su sentido, que puede ser débil en dos ocasiones y fuerte en una. Es débil en la medida en que el contexto de una norma determinada no es claro en su aplicación o si, en virtud de una escalera de rangos, la orden de un superior es totalmente indeterminada; es fuerte en la medida en que haya lugar a un juicio personal por parte del operador que aplica la orden de un superior, dada la indeterminación (leve) de la orden del mismo. Ronald Dworkin, Los derechos en serio. (Barcelona: Ariel S. A., 2012), 85.

4 Robert Alexy, Teoría del discurso y derechos humanos (Bogotá D.C: Siglo del hombre editores, 2010), 34. 
el texto; aquella alude a la hipótesis con la que un lector aborda un texto en busca de una solución jurídica a una situación determinada. Entre el texto y la hipótesis hay una relación recíproca, ya que este no tiene utilidad si no es abordado para solucionar problemas y la hipótesis solo es posible con respecto al texto, pero este círculo nada dice sobre la interpretación y solo habla de una relación concreta entre uno y otro. El segundo círculo amplía el espectro de interpretación, debido a que las normas deben ser entendidas de acuerdo con el sistema que las contiene y el sistema no puede ser comprendido si no se tienen en cuenta las normas que lo integran, es decir, se dedican a cimentar los postulados del modelo de interpretación coherente. El tercer círculo de la interpretación hermenéutica aborda la relación entre norma y situación de hecho. La norma usa un lenguaje abstracto sin rasgos característicos, mas los hechos son concretos y tienen una variedad de rasgos; en este punto, el operador judicial deberá estudiar cuál norma corresponde a los rasgos específicos de un hecho en el mundo real, para determinar si esa norma es la adecuada para ser aplicada. A pesar de teorizar la interpretación normativa, la teoría hermenéutica del Derecho se queda corta al no poder definir cuál es la interpretación correcta, o sea, la mejor argumentación en relación con la interpretación. Por eso, puede afirmarse que interpretación es argumentación.

- La coherencia es un elemento de la racionalidad de la visión de sistemas y, como tal, es un elemento esencial de la teoría del discurso jurídico racional. La concepción de la coherencia como modelo de interpretación tiene sus bases históricas en Savigny, quien entendió que las normas guardan una relación entre sí para formar una gran unidad. Toda interpretación hecha desde este modelo conlleva a que todos los casos tienen una solución dentro del sistema, lo que es erróneo, porque los sistemas no se construyen a sí mismos ni solucionan los casos por sí mismos: necesitan intérpretes y procedimientos para poder aplicar una solución; el intérprete es el juez y el procedimiento, la argumentación.

\section{H. L. A Hart y la regla de reconocimiento como regla de validez del sistema jurídico}

El modelo de los sistemas jurídicos planteado por Hart es aquel en el que los sujetos normativos obedecen órdenes respaldadas por amenazas emitidas por autoridades. Se puede identificar la regla de reconocimiento -regla secundaria que se emplea 
para la detección de reglas primarias de obligación- como una regla compleja, ya que existen diversas fuentes de Derecho así como variados criterios para identificarlo, pues dentro del sistema jurídico dicha regla no se formula en forma expresa. ${ }^{5}$

La regla de reconocimiento, entendida como forma de identificación normativa del sistema jurídico, puede aclarar el concepto de validez normativa; para tal fin, es necesario distinguir el punto de vista interno del externo, puesto que este concepto solo es visible desde el punto de vista interno. ${ }^{6}$ Así las cosas, si la regla satisface los parámetros requeridos por la regla de reconocimiento, se entenderá que aquella regla es válida y que, en consecuencia, pertenece al sistema. La eficacia, por su parte, hace referencia a que una norma es obedecida con mayor regularidad de lo que es desobedecida. ${ }^{7}$

\section{Habermas y la indeterminación del Derecho}

Habermas comienza planteando que los principios de un Estado de Derecho, junto con los derechos que este garantiza, son susceptibles de ser definidos en abstracto; sin embargo, es posible encontrarlos materializados en Constituciones históricas y en sistemas políticos. ${ }^{8}$ Los órdenes jurídicos representan las diversas formas de ejecución y realización de derechos y principios y los paradigmas jurídicos que también concurren en los sistemas jurídicos. Habermas define paradigma jurídico como aquellas ideas propias de una determinada comunidad jurídica en cuanto al

\footnotetext{
Hart establece que "en la mayor parte de los casos la regla de reconocimiento no es expresada, sino que su existencia se muestra en la manera en que las reglas particulares son identificadas, ya por los tribunales u otros funcionarios, ya por los súbditos o sus consejeros". H. L. A. Hart, El concepto de Derecho (Buenos Aires: Abeledo Perrot, 2012), 126-127.

6 En Hart, podríamos expresar que: "si se comprende este uso de una regla de reconocimiento aceptada al formular enunciados internos, y se lo distingue cuidadosamente de un enunciado fáctico externo que afirma que esa regla es aceptada, desaparecen muchas oscuridades referentes a la noción de 'validez' jurídica. Porque la palabra 'válido' es usada con más frecuencia, aunque no siempre, precisamente en tales enunciados internos, que aplican a una regla particular de un sistema jurídico una regla de reconocimiento no expresada pero aceptada". Hart, El concepto de Derecho, 128-129.

7 Los criterios de validez de la regla de reconocimiento son de dos tipos: primero, criterio supremo y segundo, criterio de regla última. El primer criterio establece que las reglas identificadas por él cuando forman parte del sistema pueden contradecir otras reglas identificadas por otros criterios; en caso de conflicto entre ellas, las demás reglas no serán reconocidas por el sistema. Por otra parte, el criterio de regla última proporciona los mecanismos para establecer la validez de otras reglas, las cuales no están subordinadas a criterios de validez jurídica establecidas por otras normas. Hart, El concepto de Derecho, 132.

8 Esto significa que estos están representados en órdenes jurídicos concretos, es decir, en forma de un simbolismo cultural que permite su interpretación y lenguaje, en un sistema de acción que permita aterrizarlos a una realidad determinada tanto jurídica como política. Jürgen Habermas, Facticidad y validez (Madrid: Trotta S. A., 1998), 263.
} 
desarrollo del sistema de los derechos y los principios del Estado en el marco de un contexto social particular para que tanto los derechos como los principios cumplan, en dicho contexto social, con las funciones que tiene asignadas en virtud de la ley.

Habermas define también un modelo social del Derecho como la teoría implícita que el sistema jurídico se hace de la realidad; dicho en otras palabras, la imagen que el sistema se hace del entorno que lo rodea. ${ }^{9}$ Desde esta concepción del Derecho como sistema jurídico, Habermas lo explica como un sistema de acción, como la totalidad de las interacciones reguladas por normas jurídicas y lo pone en contraposición a la concepción de Lühmann, quien lo define como aquel subsistema social que se especializa en la estabilización de expectativas de comportamiento, compuesto por todas las comunicaciones sociales que hacen referencia al Derecho. Habermas denota al sistema jurídico como aquellos sistemas de acción, compuestos por normas jurídicas, dentro de los cuales un conjunto de normas o actos jurídicos que versan sobre Derecho reflexivo recae sobre acciones gobernadas por normas jurídicas materiales.

Habermas parte de la anterior distinción de sistema jurídico para explicar el ámbito de estudio de la Filosofía del Derecho, encaminada a forjar una teoría discursiva del Derecho propia de órdenes jurídicos concretos, ya que la información de la que se retroalimenta está provista por el Derecho vigente, por la ley y por el precedente; en otras palabras, por aquello que se conoce como dogmática jurídica y por contextos políticos. De esta actividad también podríamos delimitar la actividad judicial como dogmática jurídica que permite un análisis del sistema jurídico, que no excluye a otras posibilidades metodológicas de análisis del mismo. Habermas sitúa la distinción aparente entre facticidad y validez dentro del ámbito propio de la administración de justicia, dado que hay una continua controversia entre el principio de seguridad jurídica y la pretensión de dictar soluciones correctas, es decir, de aplicar el Derecho como es, en el marco de la actividad judicial. ${ }^{10}$

En el marco de una teoría del Derecho, la tensión entre facticidad y validez trasciende hasta las dimensiones de vigencia y validez jurídica: la vigencia del Derecho

9 En el marco de este modelo social del Derecho, la función del paradigma jurídico es adecuar al interior de dicho entorno la realización de los derechos y los principios jurídicos del Estado de Derecho. Habermas, Facticidad y validez, 264.

10 Esto en el marco de una teoría del Derecho, que abarca no solo al sistema jurídico lato sensu, sino a los subsistemas encargados de la producción y administración del Derecho, es decir, al legislador y al juez. Así las cosas, la finalidad de la teoría del Derecho no es otra que mostrar todo el ordenamiento jurídico en conjunto. Habermas, Facticidad y validez, 266. 
garantiza la imposición de ciertas descripciones de comportamientos legalmente aceptados, lo cual garantiza la seguridad jurídica. Por otro lado, los procedimientos de aplicación y producción de normas jurídicas como Derecho prevén la legitimidad de aquellas descripciones de conductas, dado que las normas, por el simple hecho de ser normas, merecen obediencia y ser ejecutadas en cualquier momento.

Desde el punto de vista de la aplicación del Derecho, la vigencia y la validez deben ser simultáneas, puesto que los fallos judiciales ejercen el orden jurídico y satisfacen la pretensión de validez del Derecho. ${ }^{11}$ La seguridad jurídica exige decisiones que resulten consistentes con el orden jurídico vigente, entendido este último como el producto de un continuo e infinito conjunto de decisiones tanto del legislador como del juez (según sea el caso) o también de tradiciones que han de asumirse como Derecho; en este sentido, las decisiones judiciales de un caso actual pretenden validez a la luz de reglas o principios legítimos, es decir, principios y reglas contenidas o referenciadas en el orden jurídico. Esto deriva en un problema y es la racionalidad de la administración de justicia, porque se procura que dicha decisión defina la seguridad jurídica y la rectitud o corrección normativa, sin desconocer que las decisiones se toman internamente por parte del operador y que se procura que sean exteriorizadas con ciertos visos de racionalidad. Al respecto, Habermas plantea tres posturas, a saber:

- La hermenéutica jurídica. En el marco de una hermenéutica jurídica, se afirma que ninguna regla puede regular su propia aplicación. Esta postura va en contraposición al modelo clásico de aplicación judicial, según el cual un caso se subsume bajo una regla particular. En este marco, un determinado estado de cosas que estén conforme a una regla solo es constituido cuando, en virtud de la norma que lo cobija, se describe por medio de conceptos y el significado de la norma es concreto en la medida en que esta sea aplicada a un estado de cosas específico. ${ }^{12}$

Si seguimos esta idea, Habermas afirma que la hermenéutica jurídica propone una interpretación procesal, descrita de la siguiente forma: comienza

11 No solo se observa si un cúmulo de pretensiones se resuelven por vía jurídica de modo vinculante, sino que los fallos jurídicos representan decisiones coherentes y son racionalmente aceptables. Habermas, Facticidad y validez, 267.

12 En este orden de ideas, una norma se afecta de hechos del mundo de la vida en términos selectivos, o sea, de acuerdo con la relevancia que la norma estableció para tales hechos. Así, ese estado de cosas constituido por una determinada norma jamás agotará el contenido semántico de dicha norma, sino que hace valer -cumplir- en forma selectiva. Habermas, Facticidad y validez, 269. 
con una precomprensión de la relación o las relaciones existentes entre la norma y un estado de cosas presente en el mundo de la vida y, en la medida en que norma y estado de cosas se concretan en forma recíproca, se precisa la precomprensión, adquiere una posición propia en el marco de la teoría del Derecho y resuelve el problema de la racionalidad de las decisiones judiciales, al insertar en ellas la razón en el contexto histórico y tradicionalista que trate la sentencia. La precomprensión del juez está determinada por su ética, con lo que guía las relaciones entre normas con estados de cosas por principios históricos, es decir, por aquellos usos y costumbres jurisprudenciales que este tiene y que no están contenidos en una determinada norma. En este punto, la hermenéutica, convertida en teoría del Derecho, tiene en cuenta la pretensión de legitimidad de las decisiones judiciales. Esto puede obviarse haciendo referencia a principios, con el problema de que esos principios solo son legitimados en virtud de la historia procesal, o sea, del camino recorrido por el juez para fallar.

- El realismo jurídico. Las escuelas realistas del Derecho no discuten el valor descriptivo de la interpretación hermenéutica. En cambio, sí plantean una valoración diferente de la precomprensión que rige el proceso de interpretación. Las decisiones jurídicas, en la práctica, se hacen valer con argumentos extrajurídicos analizados mediante la experiencia; estos argumentos explican la discrecionalidad del juez al tomar una decisión y nos permiten pronosticar sus decisiones en términos históricos, psicológicos o sociológicos, por lo que desaparece una perspectiva hermenéutica del Derecho y se reemplaza por una descripción realista del proceso de aplicación del Derecho. En este marco, es posible describir los procesos de decisión jurídica en forma similar a los procesos políticos de poder, al dejar de lado tanto el postulado de la seguridad jurídica basado en la consistencia normativa, como un sistema de precedentes judiciales, en este caso, porque serían convenientemente rechazados en pro de la racionalidad del juez. Así, el Derecho se perfila como un instrumento de control del comportamiento, que puede fundamentarse en términos utilitaristas o en términos de economía del bienestar. ${ }^{13}$

13 Las escuelas realistas han sometido a crítica abierta que la mayoría de los casos sean decididos mediante un cuerpo consistente y correcto de normas que conforman un sistema jurídico; por otro lado, Habermas afirma que revocar abiertamente la garantía de la seguridad jurídica obligaría a la administración de justicia a renunciar a la función de estabilizar expectativas de comportamiento. La limitación de los realistas radica en que no pueden explicar cómo hacer compatible el funcionamiento del sistema jurídico con un escepticismo en cuanto al derecho propio de ellos. Habermas, Facticidad y validez, 270. 
- El positivismo jurídico. En contraposición al realismo jurídico, trata de tener en cuenta y dar razón de la función de estabilización de expectativas, sin necesidad de respaldar un tipo de legitimidad de la decisión judicial basada en tradiciones éticas. Autores como Alexy y MacCormick, partidarios de esta postura, afirman el sentido normativo propio de las proposiciones normativas, por un lado y, por el otro, la estructura sistemática propia de un sistema de reglas, cuya finalidad es la consistencia de las decisiones judiciales; se convierte así el Derecho en un sistema muy distinto al de la política. En contraste con los hermenéuticos, los positivistas resaltan aspectos como la completitud y el cierre de los sistemas jurídicos, que sirven para blindarlo de principios extrasistémicos que pretenden permearlo. La racionalidad, entonces, se determina de acuerdo con la primacía de una historia del sistema, definida por todas sus normas y decisiones válidas, según una norma fundante o "regla de reconocimiento". En el marco de un sistema autónomo, en virtud del cual se diferencian reglas primarias (aquellas que determinan el comportamiento del sistema) y reglas secundarias (reglas productoras de normas), solo puede determinarse por el cumplimiento de los preceptos y procedimientos jurídicamente establecidos para la producción de normas. ${ }^{14}$

\section{Administración de justicia y moral en Dworkin}

La tesis de reconocimiento de derechos está basada en una razón práctica presente en la historia de un sistema particular. Esta razón tiene una validez moral sustentada en una norma fundamental que exige igualdad y respeto a todos los ciudadanos. Esta norma, al igual que el "principio de derecho" de Kant y el "principio de justicia" de Rawls, establece que, conforme a los derechos, también asisten libertades subjetivas de acción. ${ }^{15}$ Para Dworkin, la "norma fundamental" no posee un estatus iusnaturalista, sino deontológico, en la medida en que la validez de los derechos es transferida a derechos institucionalmente vinculantes (o políticos) y blinda las pretensiones jurídicas de incondicionalidad. ${ }^{16}$

14 Según esta concepción, una regla determinada es válida porque es producida conforme a derecho, por la autoridad competente para ello; la legitimación del orden jurídico está supeditada a una "norma fundante" o "regla de reconocimiento" que lo legitima, sin ser ella misma susceptible de justificación racional. Habermas, Facticidad y validez, 271.

15 Sin embargo, Dworkin refuta a Rawls, en cuanto a la admisión de las partes en las condiciones de todo acuerdo nacional. Para Dworkin, la norma fundamental tiene un estatus de derecho natural, dado que es propio de los seres humanos proyectar planes y practicar la justicia. Habermas, Facticidad y validez, 272.

16 Dworkin defiende los derechos subjetivos como medios entre los cuales se justifican pretensiones frente a fines colectivos. Habermas, Facticidad y validez, 273. 
La teoría de Dworkin afirma que, en virtud de la administración de justicia, ciertos preceptos morales desempeñan un papel importante, en tanto el Derecho positivo ha asimilado contenidos morales en sí que, al ser traducidos al lenguaje jurídico, sufren una variación en su significado. Al respecto, Habermas plantea que los contenidos morales aparecen en el marco de las normas primarias, es decir, en el marco de las normas que regulan el comportamiento humano; esta regulación sufre una paulatina variación en su comportamiento, que disminuye poco a poco hasta un estado mínimo en el que, en relación con las normas jurídicas, se espera obediencia tanto al Derecho como al contenido de la norma. ${ }^{17}$ Esto significa que la moral, como criterio del Derecho, comienza tanto en la voluntad política del legislador como en la comunicación política del espacio público, con lo que se justifica que la aplicación de la moral en el Derecho se circunscribe a la traducción de contenidos morales a un determinado código constitutivo de Derecho y le otorga un tipo especial de validez. La interpretación jurídica de esos argumentos que versan en objetivos políticos y principios morales se puede llevar a decisiones bien fundamentadas, dado que los argumentos basados en principios sirven para justificar una decisión política al garantizar un derecho, ya sea individual o grupal. ${ }^{18}$

\section{Teoría del pragmatismo judicial}

Dworkin describe esta teoría de la aplicación judicial del Derecho, que afirma que los jueces siempre deben resolver los casos que les sean sometidos a estudio con miras hacia el futuro y tomar la decisión más beneficiosa para el sistema jurídico, sin tener en cuenta posiciones jurídicas anteriores. Esta concepción del pragmatismo debe estar influida por un determinado consecuencialismo, es decir, al fallar, el juez debe considerar las mejores consecuencias de su decisión para el sistema jurídico. ${ }^{19}$

17 Los criterios morales que sirven al legislador para juzgar una política impregnan el contenido del Derecho, en las formas en que esas políticas se hacen dinámicas. En este sentido, los argumentos que hacen referencia a fines pueden tener impresionantes referencias morales. Habermas, Facticidad y validez, 275.

18 Para Kelsen, el elemento sobre el que se basa la unidad de un determinado número de normas -es decir, la validez de una norma jurídica- se sitúa en otra norma de orden superior, aunque no excluye la posibilidad de situar la validez de una norma en el hecho de "haber sido establecida por alguna autoridad, pero vale recordar que la competencia dada a la autoridad para establecer las normas viene dada en normas de competencia. De esta manera la norma que valida las demás se entiende por presupuesta a pesar de no ser promulgada. Hans Kelsen, Teoría pura del Derecho (Ciudad de México.: UNAM, 2000), 201.

19 El consecuencialismo, a su vez, puede apoyarse en otras concepciones, como por ejemplo las del utilitarismo del acto, que afirman que las decisiones políticas deben propender por incrementar el bienestar de un grupo social determinado o una concepción no bienestarista, que procura las mejores consecuencias para el grupo social, basada en la eficiencia económica, o en maximización de la riqueza, para justificar así, en virtud de cualquiera de estas versiones más especificas del consecuencialismo, una versión más precisa del pragmatismo. Dworkin, La justicia con toga, 31. 
El juez que se apoya en el pragmatismo jurídico debe tener en cuenta aquellas "restricciones instrumentales"20 que haya predispuesto el Legislativo o los jueces en precedentes judiciales. Dworkin plantea así que el juez puede fallar hacia el futuro, como exigen los pragmatistas, tras un análisis exhaustivo del caso a partir de los cuatro estadios de la teoría política: en el ámbito semántico podría argumentar que el concepto doctrinal del derecho vulnerado es de carácter interpretativo; en el iusfilosófico podría sostener que la mejor explicación del derecho vulnerado se evidencia a la luz de la integridad del sistema jurídico; en el doctrinario tendría en cuenta la mejor interpretación de la práctica judicial contemporánea y esa práctica, desde la aplicación judicial, dependería de correlacionar el valor de verdad de una proposición jurídica con valores consecuencialistas que se proyectan. ${ }^{21}$

Los valores variados y complejos que justifican la práctica judicial conforman un conjunto integrado con los valores, principios y derechos, que deben ser encausados en dos ámbitos: uno doctrinal y otro correspondiente a la práctica judicial del Derecho.

Sin embargo, es importante aclarar que los valores políticos fundamentales, o sea, los valores de libertad e igualdad, no conviven en forma pacífica en el interior del sistema; por lo contrario, presentan conflictos en virtud de sus relaciones sistémicas. Este conflicto, que radica en los principios fundacionales del Estado, no presenta un modelo de decisión que permita definir cuál norma, principio o valor en conflicto es más fundamental y reduce esa elección al ámbito subjetivo del operador, es decir, del juez. ${ }^{22}$

20 En este caso, el juez debe obedecer las disposiciones del legislador y honrar las decisiones judiciales previas. En caso de que tanto las leyes como los precedentes fueran ignorados en las decisiones judiciales tomadas por una determinada autoridad judicial, la capacidad de prever comportamientos por parte del legislador y del juez se vería seriamente afectada. Dworkin, La justicia con toga, 32.

21 En contraposición a estas afirmaciones, la escuela del realismo jurídico afirma que una proposición jurídica no es susceptible de ser calificada de verdadera o falsa, sino solo de acuerdo con la expresión subjetiva; esto es, según la carga emotiva de la autoridad que emite la sentencia judicial (el juez). Con ello argumenta que buscar la verdad y la falsedad de una proposición jurídica es un absurdo, lo que hace de ese concepto doctrinal del Derecho un concepto erróneo. Esta cuestión es refutada con vehemencia por Dworkin, basado en un "equívoco" filosófico en el que presuntamente incurren filósofos políticos como Richard Rorty y Stanley Fish, que no conducen a nada más que a autorrefutar sus tesis. Dworkin, La justicia con toga, 33.

22 Al final, toda elección de alternativas en caso de conflictos entre valores fundamentales, principios o derechos es decidida por arbitrio del juez, es decir, la decisión política que soluciona el caso concreto depende de la elección subjetiva de este. Esta subjetividad, se aclara, no es por mera discrecionalidad, sino que radica en un juicio de carácter moral empleado por el juez, para elegir, en virtud de los límites normativos, la respuesta que le parece más justa, en su propia opinión. Dworkin, La justicia con toga, 36. 


\subsection{La razón comunicativa}

La normatividad, entendida como dirección vinculante de la acción, no es compatible con la razón de la acción, destinada al conocimiento, dado que tanto normatividad como racionalidad se separan al fundamentar convicciones morales en forma hipotética, momento en el que estas pueden replantearse en convicciones motivadas.

Así, las formas de comunicación presentes en el Estado de Derecho desarrollan la voluntad política, la producción de leyes y la toma de decisiones judiciales. Estas prácticas son entendidas como parte de un amplio proceso de racionalización de los mundos de la vida, contenidos en las sociedades modernas por medio de imperativos sistémicos. Esta es la reconstrucción de los diversos discursos formadores de opiniones y también base de decisiones, que contienen el poder democrático al ser ejercido en la forma de derechos.

Como respuesta a lo anterior, Habermas plantea no cerrar el entendimiento a una sola disciplina, sino mirar puntos de vista metodológicos en perspectiva, es decir:

- Observar los distintos puntos de vista tanto desde el observador como del participante.

- Mirar diversos objetivos teoréticos, o sea, reconstruir en forma comprensiva y descriptiva, que procure explicar fenómenos empíricos.

- Tener en cuenta las diferentes perspectivas derivadas de los roles sociales, es decir, observar la situación desde la óptica del juez, del legislador, del político, del burócrata o del ciudadano, según sea el caso.

- Apreciar actividades respecto a la investigación, ya sea hermenéutica, crítica, analítica u otra.

Desde de una perspectiva funcional, la moral individual, vinculada a una voluntad individual, debe ser regida por principios que, a la hora de necesitarse para una reconstrucción social del sistema de Derecho, debe ser complementada por el Derecho positivo. ${ }^{23}$

23 De acuerdo con lo descrito, la teoría del Derecho no solo estudia razones de carácter normativo, sino también de carácter moral y fuerza al Estado de Derecho a adoptar un punto de vista más profundo que los propios de las tradicionales concepciones filosóficas. Habermas, Facticidad y validez, 69. 
Renunciar a la razón práctica implica un rompimiento con el normativismo clásico en la filosofía. En el sistema presente en el mundo de la vida, que se ve un poco mermado en el concepto de acción o razón comunicativa, se erige como una teoría sociológica que estimula no solo la comprensión, sino también la explicación de fenómenos o entidades presentes en el mundo de la vida.

Sin embargo, el concepto de razón aducía a un concepto de idea, como medio de expresar fines. En el concepto de acción comunicativa, esa operación de idealizar va incluso hasta la realidad social, lo cual, desde la perspectiva de las ciencias experimentales, podría llegar a generar una confusión conceptual entre razón y realidad.

\subsection{Representaciones lingüísticas de la realidad}

En el curso del siglo XIX, cuando estaban en auge las explicaciones psicológicas por encima de las lógicas y todo tenía una determinada razón conceptual, la validez dependía de elementos fácticos presentes en la conciencia social. Como es natural, se presentaron objeciones a esa "psicologización" empírica de la ciencia, en particular de la Lógica, la Matemática y la Gramática.

Habermas cita a Frege con el fin de mostrar esa objeción a la psicologización: "No somos portadores de los pensamientos, como somos portadores de nuestras representaciones" ${ }^{24}$ En este caso, las representaciones son de un sujeto determinado. Este sujeto es susceptible de identificarse en un tiempo y un espacio particulares; a diferencia de los pensamientos que, aunque pueden trascender los límites de la conciencia individual en cuanto a su contenido material, son siempre los mismos pensamientos.

Por medio de las oraciones predictivas simples, es posible expresar la compleja estructura propia de los pensamientos respecto a objetos representados en la realidad, dado que mediante una o varias proposiciones en conjunto se puede expresar una proposición sobre un objeto o un estado de cosas y así, en el evento de que el pensamiento sea verdadero, la oración que lo manifiesta expresa un hecho determinado. Esta es la denominada conciencia representativa. ${ }^{25}$ Es el primer paso hacia el giro lingüístico, puesto que tanto los pensamientos como los estados de cosas no

\footnotetext{
Habermas, Facticidad y validez, 72.

25 En el marco de la representación solo se pueden determinar objetos, dado que tanto los estados de cosas como los hechos solo son comprensibles mediante pensamientos. Habermas, Facticidad y validez, 73.
} 
pueden formar parte del mundo material, sino solo por medio de su exposición, es decir, cuando estos son expresados mediante oraciones.

La articulación propia de los pensamientos es proposicional, o sea, mediante oraciones asertóricas simples. Así las cosas, en la estructura de la oración se evidencia la estructura del pensamiento, dado que la oración es el componente elemental, calificable de verdadero o falso, de un lenguaje gramatical, conectado por signos lingüísticos.

Esas reglas gramaticales y esos signos lingüísticos otorgan a los sucesos lingüísticos "las oraciones" en su dimensión tanto fonética como sintáctica y semántica, su determinada forma, que es estable y susceptible de ser reconocida aun si sufriese variaciones.

Todo pensamiento completo tiene un contenido, un estado de cosas susceptible de ser expresado por medio de una oración enunciativa. No obstante, se requiere un acto de juicio por parte de los sujetos personales y hablantes que, frente a un pensamiento, permita determinar la verdad o falsedad de una oración que expresa un hecho. ${ }^{26}$

En el evento en que un sujeto desarrolle una idea acerca de algo presente en la realidad, se tienen dos "mundos posibles": el sujeto que interpreta y el objeto interpretado. Sin embargo, en la historia de la filosofía se ve la imperativa necesidad de desarrollar un tercer mundo que contenga objetos intemporalmente ideales, oponible al mundo material y al mundo subjetivo. Las relaciones propias entre estos tres mundos son enigmáticas, pero se plantea que sirven para expresar la forma en que los significados y pensamientos, después de ser adecuados a hipótesis, son convertidos en objetos ideales.

En atención a su criterio sociológico, las normas jurídicas pueden dividirse en dos: normas que pueden ser legítimas por medio de la corrección del procedimiento por el que fueron creadas o por medio de una justificación material. Veamos:

- Por medio de la corrección del procedimiento. Se justifica dado el gran número de normas positivas que conforman el sistema, cuya función es servir de

26 Este juicio pone en cuestión la validez del juicio y la validez de la oración, en el momento de calificación de verdad o falsedad de un determinado pensamiento, en un particular momento ideal. Jürgen Habermas, Teoría de la acción comunicativa (Madrid: Trotta S. A., 2012), 74. 
instrumento organizacional de los subsistemas presentes frente a contextos normativos; combina así al Derecho con el dinero y el poder y lo convierte en un medio de control. La única diferenciación del Derecho ante al poder y el dinero es que el Derecho es una institución. ${ }^{27}$

- Justificación material. La validez de las normas radica en una justificación material, puesto que ellas forman parte de las "órdenes legítimas del mundo de la vida", esto es, las normas propias de todo sistema que, junto con otras normas que rigen acciones sociales determinadas, son la base de la acción comunicativa.

El Derecho moderno se caracteriza por su combinación entre principio de positivización y principio de fundamentación; mas, al comprender al Derecho como un mecanismo de control, este se libera de la carga de los fundamentalismos y le permite conectarse con el corpus normativo necesario para su justificación material. Por lo tanto, se afirma que las instituciones jurídicas forman parte de los componentes sociales presentes en el mundo de la vida y pueden ser moralizadas: estudiadas como componentes éticos en caso de algún evento especial, en el cual no se afecta el corpus normativo completo y se puede impulsar un cambio legal en el Derecho vigente en el mundo de la vida.

Así, el Derecho conectado con el dinero y el poder, en medio de su complejidad, abarca puntos de acción instituidos incluso en el Derecho formal burgués; por tal razón, las instituciones jurídicas tienen una función regulativa en el marco de un contexto político-cultural y social más amplio, ${ }^{28}$ en tanto guardan cierta relación de continuidad con las normas éticas del sistema, dado que constituyen el marco de desarrollo de las situaciones jurídicas que, dentro de las circunstancias de acción

27 Habermas entiende las instituciones jurídicas como "Las normas jurídicas que no pueden quedar suficientemente legitimadas con solo apelar, en términos positivistas, a su corrección procedimental". Habermas, Facticidad y validez, 516.

28 Quizá este planteamiento del Derecho, que puede llegar a interpretarse como de corte marxista, fue desvirtuado, ya que "el Derecho marxista" es posible bajo los siguientes parámetros: 1) todo dicho responde al interés de la clase dominante; 2) no es un método adecuado de transformación social; 3) carece de autonomía respecto de la base económica que lo determina; 4) oculta y deforma la realidad, y 5) está destinado a extinguirse. En ese orden de ideas, carece de sentido hacer un análisis interno del Derecho. Juan Pérez, "Teorías críticas del Derecho" en Enciclopedia Iberoamericana de Filosofía, ed. Carlos E. Alchourrón, José M. Méndez y Raúl Orayen (Madrid: Trotta S. A., 1997), 87-88. 
presentes en el entorno social, permiten la conformación por axiomatización de sistemas jurídicamente ordenados. ${ }^{29}$

Por lo tanto, si se demuestra la política social del Estado, los efectos de las acciones comunicativas que transmiten ámbitos de acción garantizan unas determinadas prestaciones sociales por medio de un Derecho social que pueda exigirse como medio para llegar a esas prestaciones.

\section{Sistema jurídico autónomamente cerrado}

Dworkin define las reglas como normas concretas determinadas por su aplicación específica. También explica principios como la representación de directivas jurídicas, que tienen un carácter general y además necesitan interpretación. Ambos (reglas y principios) son considerados como mandatos, cuya validez deóntica expresa el carácter de una obligación. Los principios, por un lado, no tienen una estructura teleológica y Habermas afirma que no pueden entenderse como Alexy los menciona, es decir, como "mandatos de optimización", pues con esta definición se haría difuso el sentido deontológico de una regla o principio. Ambos sirven para argumentar decisiones, tienen una función distinta desde la óptica de la lógica de la argumentación, porque las reglas pueden brindar un componente que especifica siempre las condiciones de aplicación que representan rasgos típicos de situaciones concretas, mientras los principios se pueden presentar mediante una pretensión de validez inespecífica o, en su aplicación, son restringidos por condiciones muy generales que requieren cierto grado de interpretación. ${ }^{30}$ El positivismo entiende el sistema jurídico como un sistema cerrado de reglas, determinadas en virtud de su aplicación, que se optimizan en la discrecionalidad del juez y es en este punto en donde permite la solución de indeterminaciones jurídicas en la decisión judicial. Entonces, al admitir los principios como justificación superior de una aplicación normativa, se reconocen como elementos comunes del discurso jurídico y se reevalúa el carácter cerrado del sistema jurídico y el carácter irresoluble de los conflictos normativos.

29 Esto también permite distinguir los procesos integrados de juridización que pueden surgir en el mundo de la vida. Habermas, Facticidad y validez, 517.

30 En caso de colisión entre reglas y principios, esta solo puede resolverse de dos formas: se incluye una cláusula de excepción o se declara inválida una de las reglas en conflicto. En caso de colisión entre principios, tiene preeminencia el principio más aplicable al caso concreto, sin que los principios que sean desplazados pierdan su validez por esta razón, es decir, entre principios se establece un orden en cada caso, sin que se afecte su validez. Habermas, Facticidad y validez, 278. 
En virtud de esta interpretación constructiva, los principios jamás pueden ser tomados de tradiciones acreditadas, sino que han de asumirse de acuerdo con un método, mediante un procedimiento de interpretación constructiva. En otras palabras, por medio de una teoría del Derecho que, en cada caso, realice una reconstrucción racional del Derecho vigente y lo conceptualice. Es posible que esta reconstrucción sea internamente accesible y que de ahí se deriven argumentos críticos históricamente presentes en un sistema determinado; esto supone que en el punto de donde se parta en la reconstrucción siempre habrá un elemento prejuzgador, jamás será neutro. Así las cosas, se justifica como un proceso de reconstrucción operativo para el Derecho. Entonces se justifica el modelo de Dworkin basado en reglas y principios, pues debido a una administración discursiva de justicia se asegura la integridad de las relaciones de mutuo reconocimiento que garantizan igualdad y respeto a cada ciudadano; aquí entra la interpretación constructiva y hace explícita la racionalidad del proceso de comprensión, mediante la referencia a un paradigma o un propósito particular. Con tal procedimiento de interpretación constructivista, todo juez, por principio, es capaz de proponer una decisión valida en forma ideal y ponderar la indeterminación del Derecho con la fundamentación de su sentencia mediante una teoría. ${ }^{31}$

Dworkin propone una construcción de una teoría del Derecho que procure buscar y hallar principios y objetivos válidos a partir de los cuales un orden jurídico pueda justificarse aun desde sus elementos esenciales, al añadir a dicho orden las decisiones judiciales como ingredientes coherentes. ${ }^{32}$ En este orden de ideas, se justifica la figura del juez ideal de Dworkin, el juez Hércules que, para su desempeño judicial, se sirve de dos cosas: conoce todos aquellos principios válidos y todos aquellos elementos necesarios para la justificación de sus decisiones, así como una extraordinaria visión del conjunto de factores que se entrelazan por medio de hilos argumentativos y conforman el corpus del Derecho. La reconstrucción implica una teoría selectiva, como para brindar solo una decisión correcta para cada caso. ${ }^{33}$

31 Esta teoría tiene la finalidad de reconstruir el sistema jurídico en cada caso, de modo que se justifique el Derecho vigente a partir de un conjunto ordenado de principios y así ejemplifica el Derecho en general. Habermas, Facticidad y validez, 280.

$32 \mathrm{Al}$ respecto parece válida la crítica planteada por Gunther Teubner, que afirma que, al estar sumergidos en el marco de la teoría sistémica, los sistemas han de ser capaces de adaptarse siempre a un ambiente que los soporte. Esta flexibilidad le permite responder al entorno por medio de operaciones internas que podrían derivar, en últimas, en una modificación seria de la estructura dinámica de dicho sistema.

33 En palabras de Lühmann, las expectativas jurídicas, entre las que figura la decisión judicial que ha de contener (de forma hipotética y según Dworkin) decisiones de corte moral, solo obedece a cuestiones relativas a la memoria de la sociedad, dado que el conjunto de elementos interactuantes socialmente en un momento 


\section{Conclusiones}

Al estudiar con base en la teoría del Derecho de Ronald Dworkin, las implicaciones jurídicas en cuanto al juicio moral y a la norma como tal, se determina así una relación entre ambos en cuanto a la composición del sistema jurídico. Una vez constatada esta relación, se evidenció que no era la única que podía surgir en ese momento y se procedió a compararla con otras teorías como las de Robert Alexy, que hace referencia a una teoría discursiva del Derecho, las reglas de reconocimiento de H. L. A. Hart como criterios iniciales o puntos de partida del sistema y la acción comunicativa de Jürgen Habermas, que justifica el uso de criterios morales a la hora de ejercer el Derecho, para terminar con una teoría del pragmatismo judicial, que es una interpretación de los juicios morales vistos desde una perspectiva práctica.

\section{Referencias}

Alexy, Robert. Teoría del discurso y derechos humanos. Bogotá: Siglo del Hombre Editores, 2000.

Dworkin, Ronald. La justicia con toga. Madrid: Marcial Pons S. A., 2010

Dworkin, Ronald. Los derechos en serio. Barcelona: Ariel S. A., 2012.

Habermas, Jürgen. Facticidad y validez. Madrid: Trotta S. A., 1998.

Habermas, Jürgen. Teoría de la acción comunicativa. Madrid: Trotta S. A., 2012.

Hart, H. L. A. El concepto de Derecho. Buenos Aires: Abeledo Perrot, 2012.

Kelsen, Hans. Teoría pura del Derecho. México D. F.: Ediciones Universidad Nacional Autónoma de México, 2000.

Lühmann, Niklas. El derecho de la sociedad. México D. F.: Herder, 2000.

Pérez, Juan. "Teorías críticas del Derecho" en Enciclopedia Iberoamericana de Filosofía, editado por Carlos E. Alchourrón, José M. Méndez y Raúl Orayen, 87-88. Madrid: Trotta S. A., 1997.

determinado permitirán también determinar modelos decisorios para ocasiones particulares en el futuro. Niklas Lühmann, El Derecho de la sociedad (México D. F: Herder), 179. 